\title{
A Case of Untreated Squamous Cell Lung Carcinoma May Contribute to the Occurrence of Hemophagocytic Syndrome
}

\author{
Eriko Koda ${ }^{1}$, Hiroki Nishine ${ }^{1}$, Yusuke Saiki ${ }^{2}$, Akihito Tsunoda ${ }^{1}$, Ayano Usuba ${ }^{1}$, \\ Naoki Furuya ${ }^{1}$ and Masamichi Mineshita ${ }^{1}$
}

\begin{abstract}
:
A 44-year-old man presented at our hospital to be evaluated for persistent fever and dyspnea. A chest computed tomography scan showed diffuse ground glass shadows and a left hilar tumor shadow. Upon further examination, he was found to have leukopenia, thrombocytopenia, and elevated lactate dehydrogenase and ferritin levels. He was diagnosed with both squamous cell lung carcinoma by a transbronchial lung biopsy and hemophagocytic syndrome by a bone marrow biopsy. After receiving treatment with dexamethasone and etoposide, the blood test abnormalities and performance status improved. Chemotherapy for lung cancer was initiated. He had a partial response after first-line chemotherapy and thereafter underwent left upper sleeve lobectomy.
\end{abstract}

Key words: hemophagocytic syndrome, lung cancer

(Intern Med Advance Publication)

(DOI: 10.2169/internalmedicine.5892-20)

\section{Introduction}

Hemophagocytic syndrome (HPS) is a condition in which histiocytes activated by inflammatory cytokines proliferate in the bone marrow and other tissues in the reticular system and phagocytize their own blood cells. Because the activation of inflammatory cytokines is the main cause of HPS, various clinical symptoms, such as fever, lymphadenopathy, pancytopenia, hepatosplenomegaly, hepatic dysfunction, and disseminated intravascular coagulation (DIC), are present (1). HPS is divided into primary and secondary types. Secondary HPS has been reported in autoimmune and infectious diseases as well as in malignant tumors (2). Malignant lymphoma is the most common cause of HPS (3); however, no previous case reports have reported HPS due to untreated non-small cell lung cancer. Therefore, we herein report a case of untreated squamous cell lung carcinoma that may have contributed to the occurrence of HPS.

\section{Case Report}

A 44-year-old man had experienced a fever for 3 months. He had dyspnea and a cough that began 2 weeks prior to evaluation at our hospital. His medical history revealed cutaneous lupus erythematosus when he was 33 years of age, membranous nephropathy, and he also had a 24-pack/year smoking history. The physical findings at the time of admission were as follows: height $170 \mathrm{~cm}$, weight $61.3 \mathrm{~kg}$, body temperature $38.0^{\circ} \mathrm{C}$, blood pressure $116 / 51 \mathrm{mmHg}$, heart rate $97 / \mathrm{min}$, respiration rate $20 / \mathrm{min}$, and oxygen saturation 97\% (ambient air). Rhonchi was heard bilaterally. There was no lower limb edema, rash, or joint swelling. The laboratory findings were as follows (Table): elevated lactate dehydrogenase (LDH), C-reactive protein, and ferritin levels; renal and hepatic dysfunction; coagulopathy that did not meet the diagnostic criteria for DIC; elevated interleukin (IL)-2 receptor and tumor markers CEA and SLX levels; 160-fold positive speckled pattern of anti-nuclear antibody; and two-fold positive anti-ribonucleoprotein (RNP) antibody. A chest X-ray and computed tomography (CT) showed diffuse ground

${ }^{1}$ Division of Respiratory Disease, Department of Internal Medicine, St. Marianna University School of Medicine, Japan and ${ }^{2}$ Division of Hematology and Oncology, Department of Internal Medicine, St. Marianna University School of Medicine, Japan Received: July 17, 2020; Accepted: February 8, 2021; Advance Publication by J-STAGE: March 29, 2021 Correspondence to Dr. Eriko Koda, e2koda@marianna-u.ac.jp 
Table. Laboratory Data upon Admission.

\begin{tabular}{|c|c|c|c|}
\hline WBC & $3,200 / \mu \mathrm{L}$ & CEA & $8.8 \mathrm{ng} / \mathrm{mL}$ \\
\hline Neutrocyte & $76 \%$ & SLX & $71.7 \mathrm{U} / \mathrm{mL}$ \\
\hline Lymphocyte & $17 \%$ & SCC & $1.3 \mathrm{ng} / \mathrm{mL}$ \\
\hline Monocyte & $2 \%$ & CYFRA & $8.5 \mathrm{ng} / \mathrm{mL}$ \\
\hline Eosinophils & $0 \%$ & ProGRP & $57.2 \mathrm{pg} / \mathrm{mL}$ \\
\hline Basophils & $0 \%$ & NSE & $22.1 \mathrm{ng} / \mathrm{mL}$ \\
\hline $\mathrm{RBC}$ & $510 \times 10^{4} / \mu \mathrm{L}$ & sIL2R & $4,865 \mathrm{U} / \mathrm{mL}$ \\
\hline $\mathrm{Hb}$ & $15.2 / \mathrm{dL}$ & & \\
\hline Platelets & $14.9 \times 10^{4} / \mu \mathrm{L}$ & Antinuclear antibody & \\
\hline Sodium & $115 \mathrm{mEq} / \mathrm{L}$ & Speckled pattern & $160 x$ \\
\hline Potassium & $3.9 \mathrm{mEq} / \mathrm{L}$ & Anti-DNA antibody & $4 \times$ \\
\hline Chloride & $85 \mathrm{mEq} / \mathrm{L}$ & Anti-CCP antibody & $<0.6$ \\
\hline BUN & $22.4 \mathrm{mg} / \mathrm{dL}$ & Anti-RNP antibody & $2 x$ \\
\hline Creatinine & $1.38 \mathrm{mg} / \mathrm{dL}$ & Anti-SS-B antibody & Negative \\
\hline AST & $332 \mathrm{IU} / \mathrm{L}$ & Anti-ARS antibody & Negative \\
\hline ALT & $187 \mathrm{IU} / \mathrm{L}$ & Anti-SCL-70 antibody & Negative \\
\hline ALP & $226 \mathrm{IU} / \mathrm{L}$ & MPO-ANCA & $<1$ \\
\hline$\gamma$ GTP & $67 \mathrm{IU} / \mathrm{L}$ & PR3-ANCA & $<1$ \\
\hline $\mathrm{LDH}$ & 1,362 IU/L & $\mathrm{C} 3$ & $116 \mathrm{~m} / \mathrm{dL}$ \\
\hline Total bilirubin & $0.4 \mathrm{mg} / \mathrm{dL}$ & $\mathrm{C} 4$ & $42 \mathrm{mg} / \mathrm{dL}$ \\
\hline Total protein & $5.8 \mathrm{~g} / \mathrm{dL}$ & IgG & $1,355 \mathrm{mg} / \mathrm{dL}$ \\
\hline Albumin & $1.5 \mathrm{~g} / \mathrm{dL}$ & IgG4 & $107 \mathrm{mg} / \mathrm{dL}$ \\
\hline CRP & $7.34 \mathrm{mg} / \mathrm{dL}$ & $\mathrm{CMV}$ antigen & Negative \\
\hline Ferritin & $10,570 \mathrm{ng} / \mathrm{mL}$ & Anti-EBV antibodies & \\
\hline KL-6 & $1,106 \mathrm{U} / \mathrm{mL}$ & VCA-IgM & $<10$ \\
\hline SP-A & $425 \mathrm{ng} / \mathrm{mL}$ & VCA-IgG & $80 x$ \\
\hline SP-D & $94 \mathrm{ng} / \mathrm{mL}$ & EBNA-IgG & $20 x$ \\
\hline $\mathrm{PT}$ & $95 \%$ & $\beta$-D glucan & $<2.2 \mathrm{pg} / \mathrm{mL}$ \\
\hline PT-INR & 1.03 & Blood culture & Negative \\
\hline APTT & $32.5 \mathrm{Sec}$ & Sputum culture & Negative \\
\hline APTT-control & $30.2 \mathrm{Sec}$ & & \\
\hline Fibrinogen & $590 \mathrm{mg} / \mathrm{dL}$ & & \\
\hline D-dimer & $7.2 \mu \mathrm{g} / \mathrm{mL}$ & & \\
\hline NT-proBNP & $786 \mathrm{pg} / \mathrm{mL}$ & & \\
\hline
\end{tabular}

ALP: alkaline phosphatase, ALT: alanine aminotransferase, APTT: activated partial thromboplastin time, ARS: amino acyl-RNA synthetases, AST: aspartate aminotransferase, BUN: blood urea nitrogen, CCP: cyclic citrullinated protein, CEA: carcinoembryonic antigen, CMV: cytomegalovirus, CRP: C-reactive protein, CYFRA: cytokeratin subunit 19 fragment, EBV: Epstein-Barr virus, $\gamma$ GTP: $\gamma$-glutamyl transpeptidase, KL-6: sialylated carbohydrate antigen KL-6, LDH: lactate dehydrogenase, MPO-ANCA: myeloperoxidase-anti-neutrophil cytoplasmic antibody, NSE: neuron specific enolase, NT-proBNP: N-terminal pro-brain natriuretic peptide, PR3-ANCA: serine proteinase3-anti-neutrophil cytoplasmic antibody, ProGRP: pro-gastrin releasing peptide, PT: prothrombin time, PT-INR: prothrombin timeinternational normalized ratio, RNP: ribonucleoprotein, SCC: squamous cell carcinoma associated antigen, SCL-70: scleroderma-70, sIL-2R: soluble interleukin-2 receptor, SLX: sialyl Lewis- $x-i$ antigen, SP-A: surfactant protein A, SP-D: surfactant protein D

glass shadows bilaterally and a left hilar tumor shadow (Fig. 1). The clinical course after admission is shown in Fig. 2.

After admission, additional tests for viral pneumonia, fungal infection, alveolar hemorrhage, acute respiratory distress syndrome, acute interstitial pneumonia, and carcinomatous lymphangitis were carried out. Antibiotics (sulbactam and/or ampicillin) were also administered. Testing was performed and antibiotics were administered to determine the cause of the diffuse ground glass shadows. $\beta$-d-glucan, blood cul- tures, and sputum cultures were negative. The patient also tested negative for viral infections (Epstein-Barr virus and cytomegalovirus). The anti-DNA antibodies were negative but the speckled pattern of anti-nuclear antibodies and antiRNP antibodies was positive. The possibility of a mixed connective tissue disease (MCTD) was considered but the diagnostic criteria were not met (4) because the results of joint and skin examinations were normal and the patient did not have pulmonary hypertension.

On day 6 of hospitalization, lymphocytopenia (WBC 


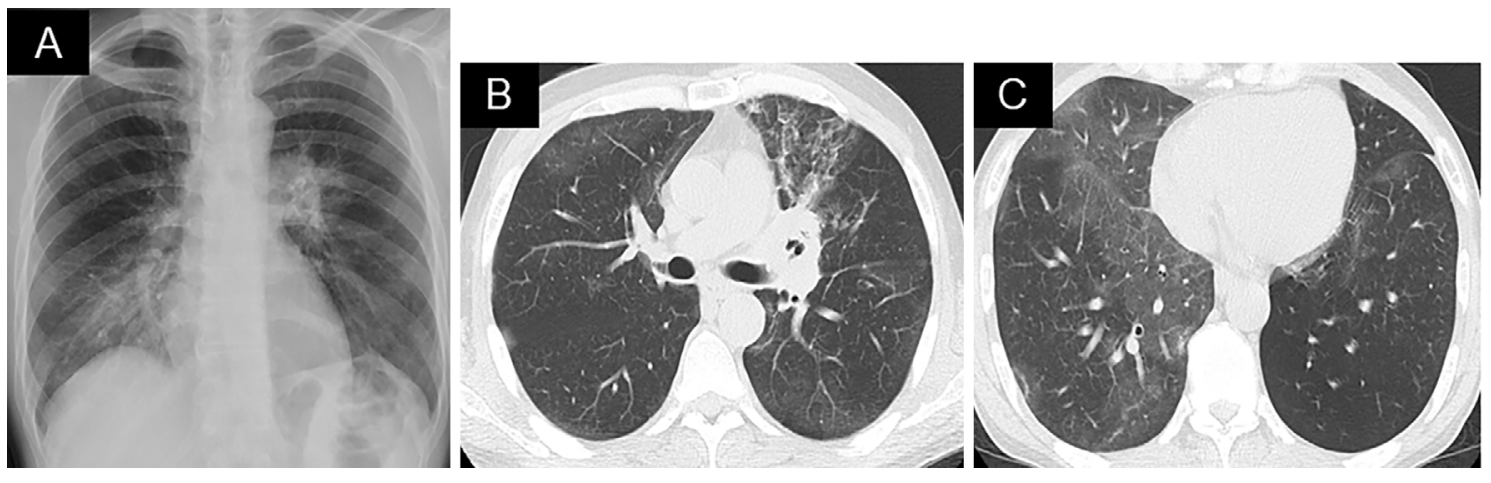

Figure 1. Chest imaging upon admission. (A) A chest radiograph showing a lower lobe reticulated shadow and left hilar tumor shadow. (B, C) A computed tomography scan showing diffuse ground glass shadows on both lungs and a left hilar tumor shadow. There is no mediastinal lymphadenopathy, lobar or interlobular wall thickening, or tractional bronchiectasis.

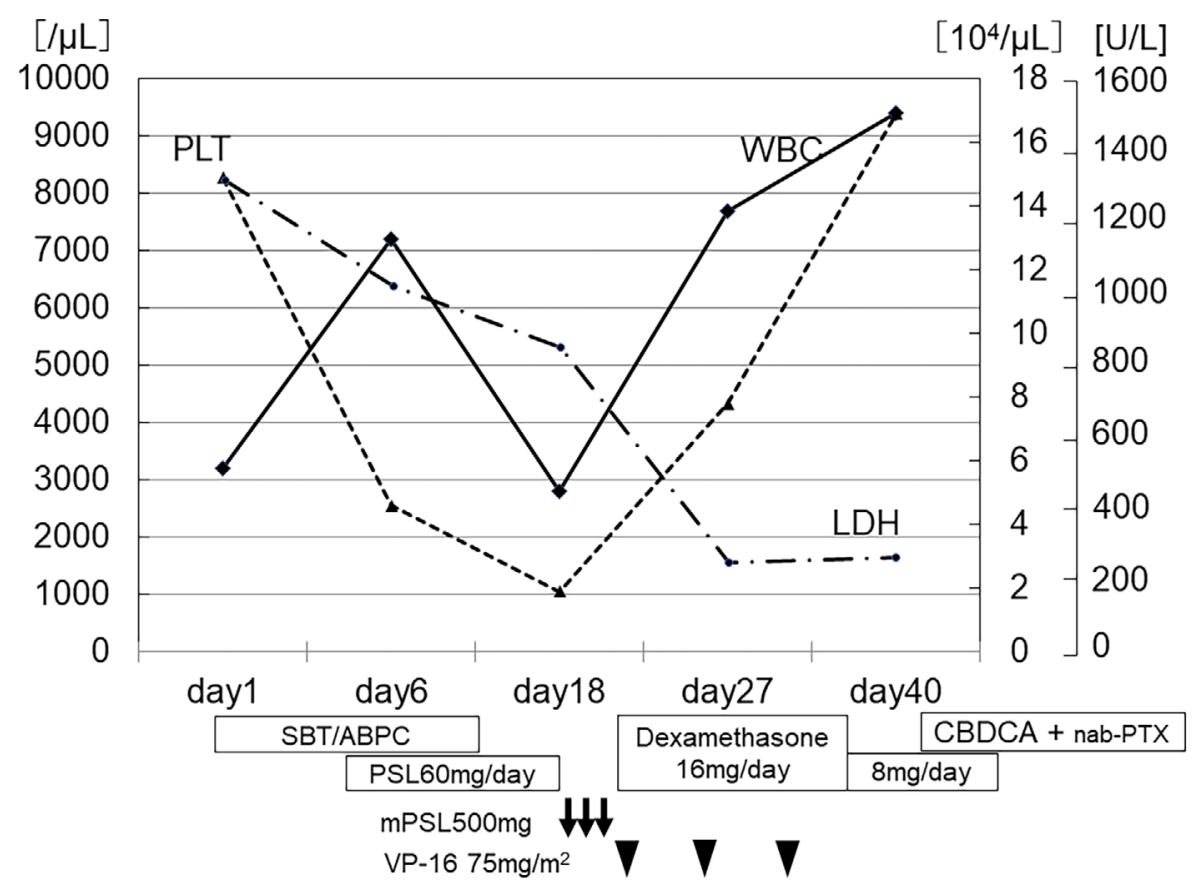

Figure 2. The clinical course after admission. The steroid pulse therapy improved the fever and chest imaging findings. After the administration of dexamethasone and etoposide, the white blood cell and platelet counts increased. CBDCA: carboplatin, mPSL: methylprednisolone, nab-PTX: nab-paclitaxel, PSL: prednisolone, SBT/ABPC: sulbactam/ampicillin, VP-16: etoposide

$7,400 / \mu \mathrm{L}[3 \%$ lymphocytes]) and thrombocytopenia (4.6x $\left.10^{4} / \mu \mathrm{L}\right)$, elevated D-dimer $(21.6 \mu \mathrm{g} / \mathrm{mL})$, and elevated TAT $(28.0 \mathrm{ng} / \mathrm{mL})$ were identified, and DIC was suspected (5). Therefore, thrombomodulin and $1 \mathrm{mg} / \mathrm{kg}$ of prednisone were administered; however, the patient's condition worsened. On day 15 of hospitalization, a bone marrow biopsy was performed to examine the cause of the two blood cell lineages with cytopenia and DIC and suspected hematologic diseases, especially HPS and intravascular lymphoma. The bone marrow results showed a nucleated cell count of $4.3 \times 10^{4} / \mu \mathrm{L}$, a megakaryocyte count of $30 / \mu \mathrm{L}$, and macrophages that phagocytized red blood cells, platelets, and neutrophils, thus leading to the diagnosis of HPS (Fig. 3).
Transbronchial biopsy (TBB) was performed to investigate the left hilar tumor lesion. Squamous cell carcinoma was confirmed pathologically, and cT3N1M0 stage IIB squamous cell lung carcinoma was diagnosed (Fig. 4). Although flow cytometry was performed on TBB and bone marrow biopsy specimens to differentiate intravascular lymphoma, no abnormal cells were found and lymphoma was therefore excluded. Other etiologies of HPS were ruled out besides lung cancer. Therefore, HPS may have occurred due to lung cancer. Steroid pulse therapy was initiated. Although a slight improvement in the fever and ground glass shadows was observed, there was no increase in the platelet count. We commenced treatment with dexamethasone and 


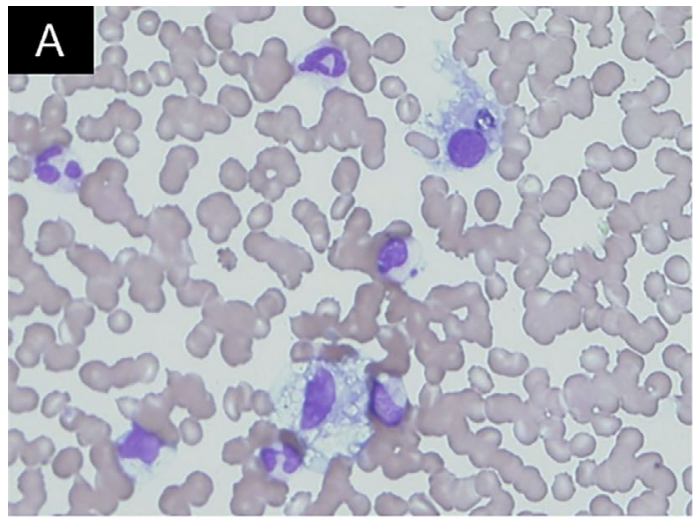

$(\times 400)$

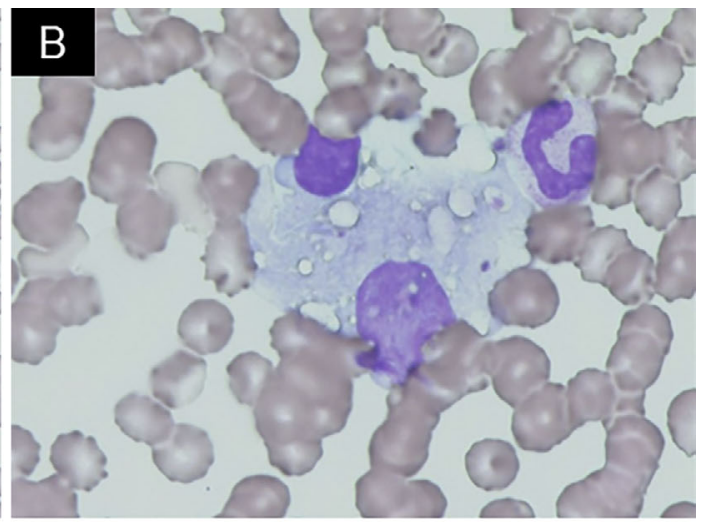

$(\times 1000)$

Figure 3. (A, B) A bone marrow biopsy specimen. Nucleated cell counts of $4.3 \times 10^{4} / \mu \mathrm{L}$, megakaryocyte count of $30 / \mu \mathrm{L}$, and macrophages that phagocytized red blood cells, platelets, and neutrophils, leading to the diagnosis of hemophagocytic syndrome.
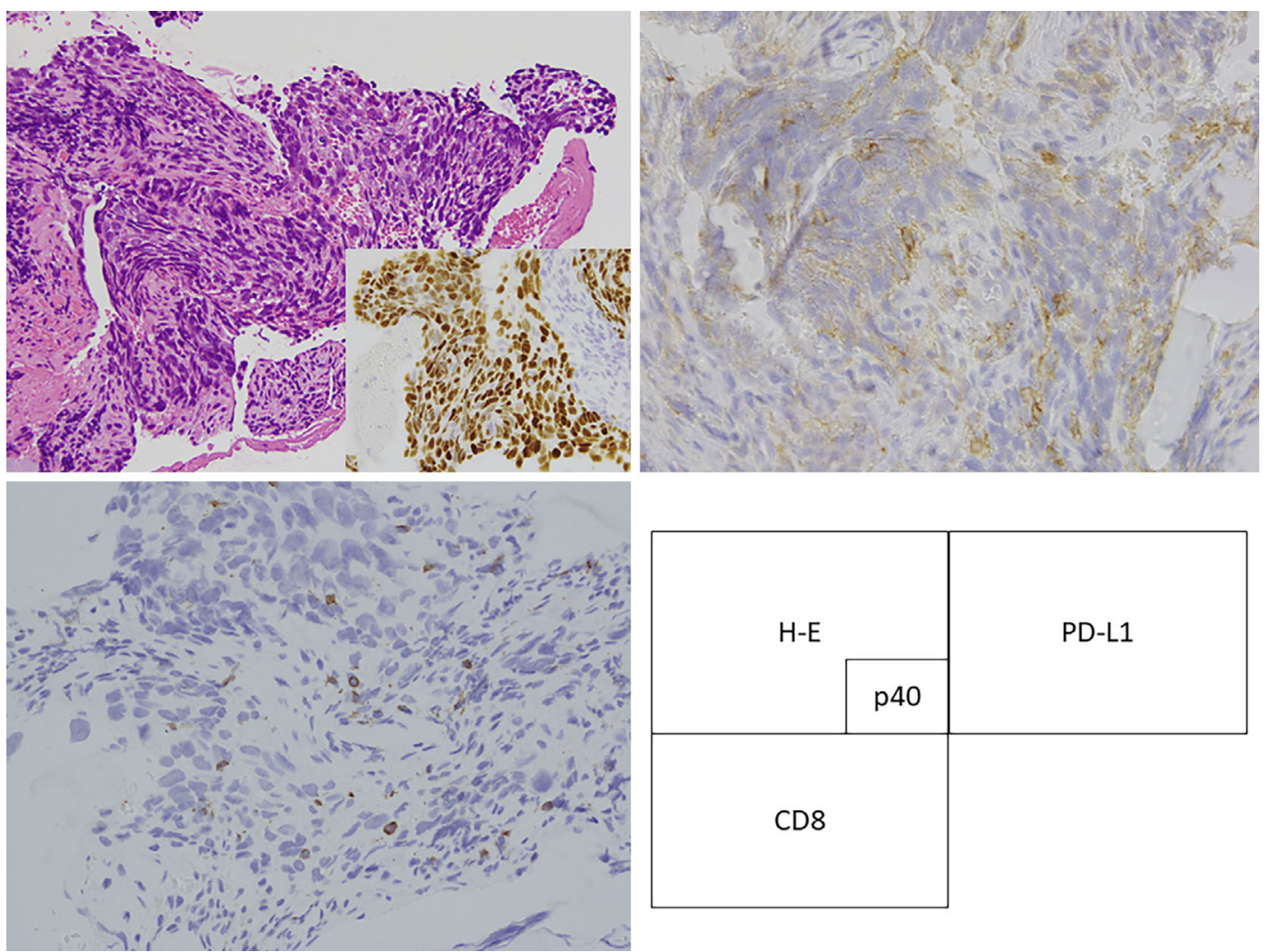

Figure 4. The pathological findings of the hilar tumor. Hematoxylin and Eosin staining showed increased tumor cell growth and positive $\mathbf{p 4 0}$ staining thus, the patient was diagnosed with squamous cell carcinoma. Both PD-L1 and CD8 staining were weak.

etoposide twice a week in accordance with the HLH-2004 protocol (2). The platelet count increased after the administration of dexamethasone and etoposide, and the ground glass shadows improved (Fig. 5).

Since the performance status of the patient was not expected to improve unless the lung cancer, which was suspected in the etiology of HPS, was treated, chemotherapy was administered to the patient for inoperable stage IIA (cT 2aN1M0) lung cancer. On day 42 of hospitalization, chemotherapy with carboplatin and nab-paclitaxel was initiated.
Nab-paclitaxel on day 15 in the first course of chemotherapy was skipped, because of grade 2 thrombocytopenia, as recommended by the Common Terminology Criteria for Adverse Events. There were no findings suggestive of HPS, such as blood cell cytopenia affecting more than two lineages and an elevation of $\mathrm{LDH}$ or the ferritin levels. Dexamethasone was discontinued before the second course of chemotherapy commenced. The patient's general condition was stable, and he was discharged on day 79 of hospitalization. 

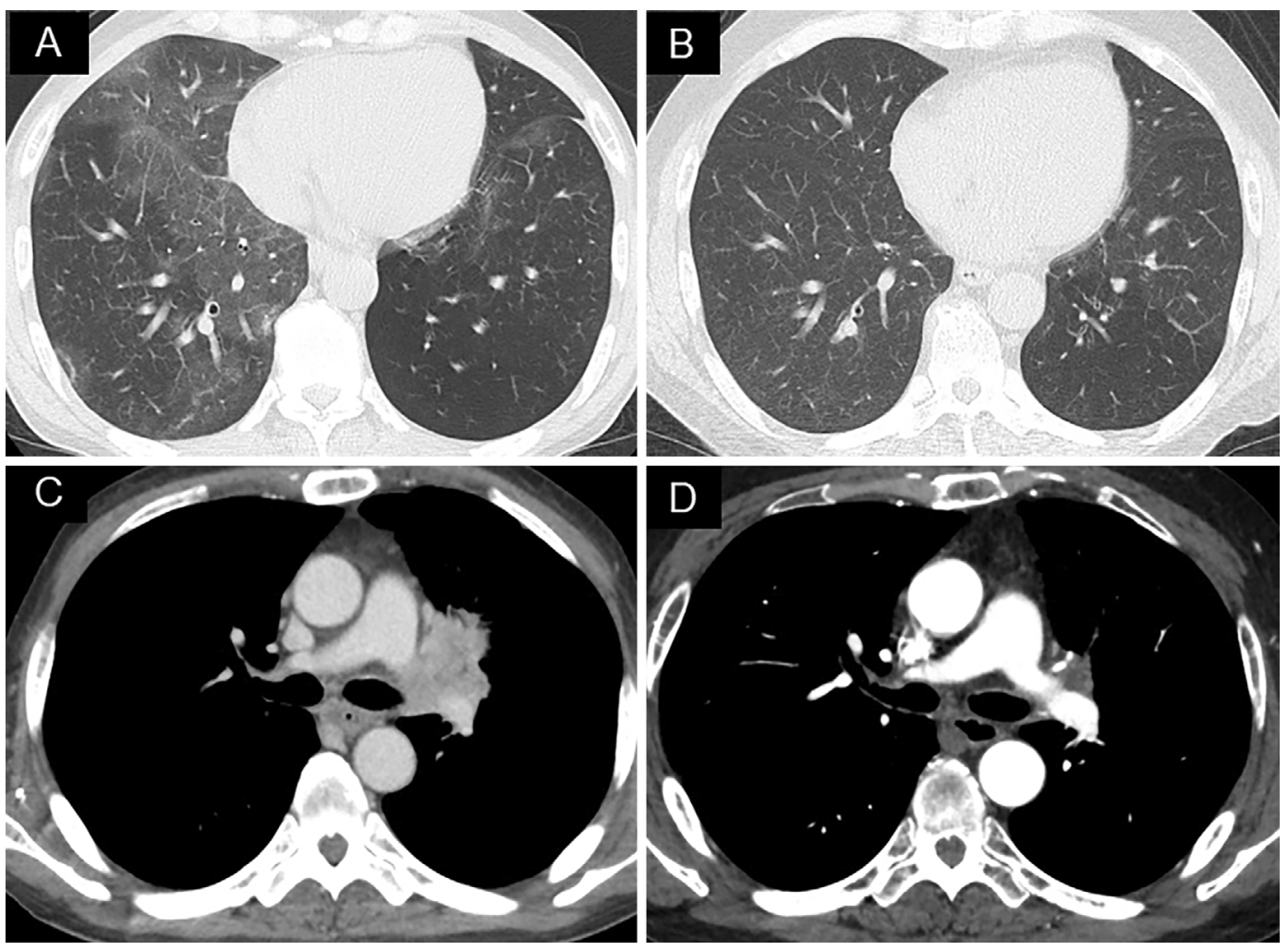

Figure 5. Clinical course based on chest computed tomography findings. (A) Upon admission, ground glass shadows were identified. (B) After treatment of HPS, ground glass shadows improved. (C) Upon admission, a left hilar tumor shadow was identified. (D) After four courses of first-line chemotherapy there was a partial response as indicated by a reduction in the tumor size.

After four courses of first-line chemotherapy there was a partial response as indicated by a reduction in tumor size (Fig. 5). The patient underwent a left upper lobe sleeve lobectomy as a curative treatment. A pathologic evaluation of the resected specimen showed tumor fibrosis but no malignant findings. To date, 16 months after sleeve lobectomy, the patient has not experienced any disease recurrence. The pathological findings of the surgical specimens showed no residual tumor.

\section{Discussion}

This is the first report of HPS in a patient with untreated non-small cell lung cancer. HPS often occurs secondary to infection, malignant tumors, autoimmune diseases, and drug use $(2,3)$. Malignant lymphoma is the major etiology of HPS in malignant diseases, while solid tumors are rarely reported. $\mathrm{CD}^{+} \mathrm{T}$ cells may be involved in the development of HPS. The risk of HPS in patients with malignant disease is thought to be high because of the increased production of cytokines, such as IL- 6 and tumor necrosis factor- $\alpha$, which tend to trigger a cytokine storm; however, the detailed mechanism of HPS has not yet been established $(2,6)$. There are several reports of HPS caused by anticancer drugs (7-10). In particular, pembrolizumab, an immune checkpoint protein inhibitor for lung cancer, is a monoclonal antibody that targets the programmed cell death-1 (PD-1) re- ceptor. By binding to PD-1 on activated T cells, the binding of pembrolizumab to PD-ligand 1 (PD-L1) on tumor cells is inhibited, resulting in the inhibition of activated $\mathrm{T}$ cells. This mechanism can cause hematologic disorders, such as hemolytic anemia, pure red cell anemia, and HPS, as a result of T cell activation. In this case, the expression of both PD-L1 and CD8 was low and the possibility of symptoms being caused by natural antigenicity was also low.

According to HLH-2004 (2), a HPS diagnosis can be given when one of the following two criteria are met: 1) a molecular diagnosis consistent with HLH or 2) the diagnostic criteria for HLH is fulfilled, which requires five of the following eight criteria being met: fever; splenomegaly; cytopenia affecting two of three lineages in the peripheral blood (hemoglobin $<90 \mathrm{~g} / \mathrm{L}$, platelets $<100 \times 10^{9} / \mathrm{L}$, neutrophils $<1.0 \times 10^{9} / \mathrm{L}$ ); hypertriglyceridemia and/or hypofibrinogenemia; hemophagocytosis in the bone marrow, spleen, or lymph nodes; low or absent NK cell activity; ferritin $>500$ $\mu \mathrm{g} / \mathrm{L}$; and soluble IL-2 receptor $>2,400 \mathrm{U} / \mathrm{mL}$. In this patient, four criteria (fever, hemophagocytosis in bone marrow, ferritin, and IL-2 receptor) were met. Although the patient did not completely meet the diagnostic criteria they were diagnosed with HPS after consultation with a hematologist because of the clinical course and hemophagocytosis in the bone marrow. Bacteriological and virological tests were negative. Lymphoma was excluded after a bone marrow biopsy and flow cytometry. ANCA and anti-RNP antibodies 
were positive upon admission but active autoimmune disease was not suspected as a result of a medical examination by a rheumatologist, and the main cause of HPS was therefore established as being the presence of lung cancer. However, ANCA and anti-RNP antibodies were negative at the time of diagnosis of cutaneous lupus erythematosus. Thus, we cannot exclude the possibility that autoimmune diseases, such as MCTD, were one of the triggers for the development of HPS. In a study by Rugien è et al. (11), the authors found that ANCA was positive in $22.3 \%$ of patients with carcinoma, and tumor-associated rheumatic syndrome was present in $2.65 \%$ of patients. In our case, the positive ANCA may have been caused by both previous autoimmune diseases and carcinomas.

In patients with HPS, pulmonary lesions are present in approximately half of cases, and CT findings show interstitial shadows with centrilobular granulation, well-defined consolidation, and focal ground glass shadows, which are common. Pleural effusion and mediastinal lymphadenopathy are also present in approximately half of cases (12). In this patient, the ground glass shadow was consistent with HPS. The differential diagnosis of the ground glass shadow in this patient was viral or bacterial pneumonia, drug-induced pneumonia, intravascular lymphoma, and collagen disease-related interstitial pneumonia. Surgical specimens from the area matching the frosted glass shadow showed a mixture of normal alveolar structures and areas of edema-like changes with a conspicuous congregation of alveolar macrophages and lymphocytes with no malignant findings, which may reflect the fact that the patient had experienced repeated bouts of pneumonia.

The basis for treatment of secondary HPS is improvement of the underlying disease and deviant immune regulation, such as hypercytokinemia. Because of the patient's poor general condition, he was unable to receive prior treatment for lung cancer. After treatment with dexamethasone and etoposide, blood test results and the performance status showed improvements. The patient recovered from potentially fatal DIC and HPS and thereafter appropriate lung cancer treatment was initiated.

We managed a case of HPS caused by untreated lung squamous cell carcinoma. The mechanism of HPS is not currently well-understood and patients with malignant tumors are often unaware that their blood test results can be easily confused for myelosuppression from treatment. In patients with solid tumors as well as malignant lymphoma, it is important to suspect HPS and provide early treatment and intervention when fever, elevated LDH, and two or more cytopenia cell lineages are present.

The authors state that they have no Conflict of Interest (COI).

\section{References}

1. Fishman DN. Hemophagocytic syndromes and infection. Emerg Infect Dis 6: 601-608, 2000.

2. Henter JI, Horne A, Aricó M, et al. Diagnostic and therapeutic guidelines for hemophagocytic lymphohistiocytosis. Pediatr Blood Cancer 48: 124-131, 2007.

3. Ishii E, Ohga S, Imashuku S, et al. Nationwide survey of hemophagocytic lymphohistiocytosis in Japan. Int J Hematol 86: 58-65, 2007.

4. Binita S, Yasir AK. Mixed connective tissue diseases. 3rd ed. StatPearls Publishing, 2011: 3-6 (in Japanese).

5. Japanese Society of Thrombosis and Haemostasis DIC Diagnostic Criteria. 2017 Edition. (in Japanese).

6. Esper DH, Harb WA. The cancer cachexia syndrome: a review of metabolic and clinical manifestations. Nutr Clin Pract 20: 369376, 2005.

7. Okawa S, Kayatani H, Fujiwara K, et al. Pembrolizumab-induced autoimmune hemolytic anemia and hemophagocytic lymphohistiocytosis in non-small cell lung cancer. Intern Med 58: 699-702, 2019.

8. Akagi Y, Awano N, Inomata M, et al. Hemophagocytic lymphohistiocytosis in a patient with rheumatoid arthritis on pembrolizumab for lung adenocarcinoma. Intern Med 59: 1075-1080, 2020.

9. Tatsuta T, Hoso N, Takagi T, et al. A case of small cell lung cancer with hemophagocytic syndrome. Nihon Naika Gakkai Zasshi (Journal of Japanese Society of Internal Medicine) 94: 756-758, 2005 (in Japanese).

10. Nezu K, Takahashi H, Matsuoka K, Sagawa T, Sakai K. A case of hemophagocytosis occurred early after surgery for primary lung cancer. Nihon Rinsho Geka Gakkai Zasshi (The Journal of the Japan Surgical Association) 68: 2476-2481, 2007 (in Japanese).

11. Rita R, Jolanta D, Eduardas A, et al. Prevalence of paraneoplastic rheumatic syndromes and their antibody profile among patients with solid tumours. Clin Rheumatol 30: 373-380, 2011.

12. Seguin A, Galicier L, Boutboul D, Lemiale V, Azoulay E. Pulmonary involvement in patients with hemophagocytic lymphohistiocytosis. Chest 149: 1294-1301, 2016.

The Internal Medicine is an Open Access journal distributed under the Creative Commons Attribution-NonCommercial-NoDerivatives 4.0 International License. To view the details of this license, please visit (https://creativecommons.org/licenses/ by-nc-nd/4.0/).

\section{(C) The Japanese Society of Internal Medicine Intern Med Advance Publication}

